\title{
NEUROÉTICA Y EDUCACIÓN MORAL: LOS RETOS EDUCATIVOS PLANTEADOS DESDE LA NEUROCIENCIA
}

\author{
Jezabel Rodríguez Pérez \\ jezabelrodriguez.rpf.ull@gmail.com
}

\section{RESUMEN}

Tomando como referencia la obra de A. Cortina y otros autores como Piaget, Sinnot o Kolhberg, el presente artículo pretende analizar las repercusiones que la neuroética, como disciplina en auge de las neurociencias, tiene en el ámbito de la filosofía y la educación moral. Dichas repercusiones conciernen a la evidencia de un soporte biológico o neuronal que determina tanto la conducta ética como el razonamiento moral. Ante tal situación, dos son las principales posturas enfrentadas: de un lado, aquella que concibe que la moralidad ha de pasar a ser un asunto de sociobiólogos; de otro, aquella que mantiene que la moralidad es irreductible a la química neuronal, por lo que sigue exigiendo un compromiso filosófico.

PALABRAs ClaVE: neuroética, razonamiento moral, psicología cognitiva, educación moral, psicología de la educación.

\section{NEUROETHICS AND MORAL EDUCATION: \\ THE EDUCATION CHALLENGES ARISING \\ FROM THE NEUROSCIENCE}

\section{Abstract}

The present article intends to analyze the repercussions that neuroethics, as a growing discipline of neurosciences, has in the field of philosophy and moral education. These repercussions concern the evidence of a biological or neuronal support that determines both ethical behavior and moral reasoning. Faced with this situation, there are two main opposing positions: on the one hand, that which conceives that morality has to become a matter of sociobiologists; from another, the one that maintains that morality is irreducible to neuronal chemistry, so it continues to demand a philosophical commitment.

KEYWORDs: neuroethics, moral reasoning, cognitive psychology, moral education, educational psychology. 


\section{INTRODUCCIÓN}

La neuroética es concebida en la actualidad como una de las áreas de investigación con mayor relevancia e implicación social; ello se debe, en gran medida, al cambio de paradigma psicopedagógico y ontológico que sus premisas suponen. Nacida como resultado de los avances neurocientíficos, la neuroética no solo ha puesto sobre la mesa la necesidad de reconsiderar las bases éticas de la condición humana; también ha traído consigo el reto de postular teorías éticas que distan de las fraguadas en la tradición filosófica. Esto último supone que las bases teóricas que servían como soporte de la conducta moral se han visto afectadas; de ahí la necesidad de revisarlas o examinar el suelo ontológico que las nutre.

Teniendo en cuenta lo anterior, una de las cuestiones que más debates genera en la neuroética radica en el rol que con ella adquiere la educación moral. Y es que, en la medida en que dicha disciplina ha venido a mostrar las bases neuronales implicadas en la conducta moral, el estatus de la formación ética cambia. En efecto: una educación moral que tenga en cuenta los fundamentos biológicos de la conducta difiere de aquella otra que no los tome en consideración, o que suponga que los razonamientos morales son fruto del libre arbitrio. En este sentido, el debate neuroético y educativo actual se constituye sobre la base de dos grandes posiciones enfrentadas: de un lado, aquellos que consideran que la ética solo ha de concernir a los sociobiólogos; de otro, aquellos que, subrayando el carácter irreductible del razonamiento moral, defienden la necesidad de la filosofía.

Pues bien, en las próximas páginas analizaremos las premisas que soportan ambas posturas, mostrándonos simpatizantes con la segunda. $Y$ es que, tal y como argumentaremos, la neuroética deja muchas cuestiones sin responder, sobre todo en lo que a las bases ontológicas de la ética se refiere. He ahí la razón por la cual estimamos necesario poner en diálogo la filosofía con la neurociencia. Sobre la base del mismo, esbozaremos nuestra tesis principal: una educación moral o formación ética solo será plenamente posible ante la consideración del humano como un ser adaptable, es decir, abierto al aprendizaje de modos de comportamiento y pautas de razonamiento.

En resumen: el presente artículo tiene como principal objetivo plantear la necesidad de una educación moral basada en el diálogo entre la neuroética y la filosofía. Hablamos de una educación que, atendiendo las diferencias culturales de las sociedades actuales, trace horizontes de pedagogía común. Con este fin, tomaremos en especial consideración las contribuciones de filósofos como A. Cortina y de neurobiólogos como Damasio.

En aras de exponer lo más claramente nuestro texto, este se distribuirá en cuatro apartados: si bien los dos primeros tratan por separado los marcos neuroéticos y educativos puestos en juego, el tercero los aborda conjuntamente con el fin de analizar las posibilidades que ellos nos ofrecen a la hora de plantear una educación moral alternativa. En un último apartado, examinaremos en qué medida la educación moral se constituye como un requisito indispensable para el logro de una sociedad democrática sana. 


\section{NEUROÉTICA, ¿DE DÓNDE VIENE Y HACIA DÓNDE VA?}

Si bien antes del siglo xx hubo algunas referencias con respecto a términos como neuroeticista o neuroética, no fue hasta el año 2002 cuando dicho concepto se constituyó formalmente en un congreso celebrado en San Francisco -el cual tenía por rótulo Neuroética: esbozando un mapa del terreno ${ }^{1}$-. A partir de este momento, la neuroética empezó a concebirse como una disciplina derivada de las neurociencias, en particular, y de las ciencias de la naturaleza, en general.

Habida cuenta de que la neuroética supone enlazar campos tan aparentemente divergentes como la ética y la neurología, cabe preguntarnos lo siguiente: ¿̨de qué manera el auge de las contribuciones neuroéticas incide en la redefinición de los ámbitos disciplinares ético y biológico?; ¡en qué medida el auge de la neuroética desemboca en una reconfiguración de las concepciones ético-civiles, así como en una reformulación de los planes educativos morales? Con la finalidad de responder a estos interrogantes, presentaremos a continuación una serie de apartados que establecerán tanto el contexto científico que precede a la neuroética como sus principales aportaciones y puntos críticos.

\subsection{NeUroÉtica Y NEUROCIENCIAS: CONTEXTUALIZACIÓN}

El marco de trabajo neurocientífico surge en la década de los 90 como un ámbito de la ciencia que se preocupa por estudiar la estructura y el funcionamiento del cerebro. La repercusión sociopolítica de sus primeros descubrimientos fue tal que el propio George Bush "padre» hizo alusión a la Década del Cerebro en un congreso celebrado en EE. UU. (17 de julio de 1990); preludió con ello el nuevo período de crecimiento tecnocientífico que se aproximaba ${ }^{2}$.

La neurociencia, como base de un nuevo paradigma científico, vino a incluir una amalgama de disciplinas eminentemente variadas; no solamente relativas a la biología, como son la neuroanatomía, la neurofisiología o la neuroembriología, sino también referidas al tratamiento farmacológico (neurofarmacología) o a las ciencias del comportamiento (psicología). Con el tiempo, de la rama neurocientífica brotarían dos nuevas e incipientes vertientes: la neuroética y la neuropolítica; allá donde la primera aborda las bases neuronales implicadas en la constitución ética, la segunda indaga sobre los patrones psicológicos y neuronales de los perfiles políticos ${ }^{3}$.

Dicho lo cual, cabe matizar que la neuroética no se reduce meramente al análisis de las bases cerebrales, anatómico-neuronales, que puedan estar más o menos implicadas en la confección del entramado ético. Aparte de esta tarea, su campo de

1 A. Contina, «Neuroética: ¿Las bases cerebrales de una ética universal con relevancia política?», Revista de Filosofía Moral y Politica, 42, 2010, pp. 129-130.

2 Ibidem, pp. 129-131.

${ }^{3}$ En palabras de Cortina, la neuropolítica viene a ser el intento de estudiar los determinantes neurobiológicos de las elecciones politicas y de los posicionamientos ideológicos. Ibid., p. 16. 
estudio abarca otras actividades tales como el estudio de la normativa moral que ha de regir las investigaciones científicas sobre el cerebro. En este sentido, diríamos que el concepto neuroética encierra un doble sentido, tal y como enfatiza Cortina:

[La] neuroética se pregunta por las condiciones éticas en las que deben llevarse a cabo tanto las investigaciones neurocientíficas como la aplicación de sus resultados para no violar los derechos humanos [...]. Pero además los descubrimientos sobre el funcionamiento del cerebro han abierto un segundo frente de cuestiones en el campo de la ética: si existen unos códigos inscritos en nuestro cerebro que son los auténticos códigos morales, [...] si somos libres o si, por el contrario, estamos determinados a actuar por nuestro cerebro, [...] qué se seguiría para la educación de las respuestas que pudiéramos dar a estas preguntas ${ }^{4}$.

Tomando esto en consideración, parece lógico estimar que la neuroética, lejos de permanecer enclaustrada en el marco neurocientífico, constituye una temática de interés para disciplinas tan diversas como la psicología evolutiva, la pedagogía, la filosofía, la sociología o la antropología, entre otras.

Habida cuenta del límite espacial con el que contamos, en las presentes páginas nos enfocaremos en las repercusiones filosóficas y pedagógicas de la neutoética. Tal enfoque supone, como hemos venido sugiriendo, una comprensión de la misma como disciplina que estudia las bases neuronales del comportamiento ético y el razonamiento moral. Aclarado esto, cabe continuar con nuestra exposición.

\subsection{LA NEURoÉtiCA: PUNTO DE ENCUENTRO ENTRE EL FUNCIONAMIENTO NEURO- NAL, LA CONDUCTA ÉTICA Y EL RAZONAMIENTO MORAL}

Siguiendo la definición que anteriormente dimos, las contribuciones que desde la neuroética se gestan, si bien son variadas y complejas, se articulan principalmente en torno a la neurobiología y su conexión con el razonamiento moral. De ahí que sus aportaciones más relevantes arraiguen en el descubrimiento de una base neuronal de la conducta ética -así como de su correlato: el ya mencionado razonamiento moral-.

Adviértase la importancia de lo aquí sugerido: gracias a una ingeniería cada vez más refinada, las técnicas de neuroimagen han permitido constatar la correspondencia entre la activación de determinadas zonas cerebrales y el procesamiento de información de carácter ético. Más específicamente, las regiones orbitales y medial del córtex prefrontal parecen tener un rol fundamental en la denominada cognición moral, esto es, en la valoración de situaciones donde las categorías éticas están inmiscuidas 5 .

\footnotetext{
4 Ibidem, pp. 15-16.

5 Ibidem, p. 136.
} 
Nótese que lo que está en juego con estos descubrimientos es la posibilidad de plantear algo así como una ética universal; un planteamiento, por lo demás, que no resulta ajeno al pensamiento filosófico ${ }^{6}$. Dicho planteamiento viene a articularse racionalmente de la siguiente manera: puesto que todo ser humano está forjado por el mismo aparato biológico, y dado que este aparato biológico constituye la base de la conducta ética y el razonamiento moral, resulta coherente defender la posibilidad de una ética universal -esto es, una normatividad ética que trascienda las fronteras culturales e históricas-.

La pregunta clave que desde las comunidades científica y filosófica se fragua con todo ello es la siguiente: ¿̇hasta qué punto la neurociencia -en general-y la neuroética -en particular - tienen la llave para abrir la puerta de un imperativo ético universal?, ¿y en qué lugar deja todo ello a la filosofía, como disciplina que tradicionalmente trataba lo relativo a la ética, y a la educación, como área capaz de forjar individuos éticamente virtuosos?

Realizando un análisis detallado de las posturas que en relación con las preguntas anteriores se han debatido, caeremos en la cuenta de que existen principalmente dos para cada una de ellas. En lo que respecta a la primera pregunta, encontramos una oposición entre aquellos que defienden la posibilidad de un marco ético universal -más allá de las diferencias culturales- y aquellos que estipulan que no, que tal universalidad biológica no es aplicable a la diversidad cultural sin violencia. En lo que se refiere a la segunda cuestión, encontramos la contraposición entre aquellos que, de un lado, consideran que la filosofía ya no tiene cabida en los debates neuroéticos (la biología se convierte así en fundamento causal e inequívoco de la ética) y aquellos que, de otro lado, estiman que la filosofía y la neuroética han de ir de la mano.

Un ejemplo de estas últimas posturas lo encontramos respectivamente en los autores E.O. Wilson ${ }^{7}$ A A. Cortina; allá donde el primero aboga por una ruptura con todo tipo de postulados teológicos y filosóficos en pos de lograr una ciencia biológica que resuelva exclusivamente los asuntos éticos, la segunda defiende el carácter materialmente irreductible del êthos humano. En otras palabras: Cortina critica el reduccionismo científico o $\operatorname{cognitivo~}^{8}$ que una postura como la de Wilson implica; de ahí que ella insista en el carácter interdisciplinar de las aportaciones neuroéticas, así como en la condición dialécticamente constitutiva del organismo y el medio?.

Con respecto a la determinación biológica de la ética cabe decir que la postura promovida por Cortina, si bien acepta la existencia de una base neuronal en la conducta moral, considera que la complejidad axiológica y deontológica es resultado

${ }^{6}$ El máximo exponente o autor paradigmático a este respecto es, como sabemos, Inmanuel Kant (1803), Tratado de pedagogía, Bogotá, Ediciones Rosaristas, 1985. Título original: Über pedagogik.

7 Wilson, E.O. (1978), On Human Nature, Cambridge, Mass., Harvard University Press.

${ }^{8}$ Cortina, op. cit., 2011.

9 C.J. Castrodeza, «De la realidad biológica a la biologización de la realidad: la nueva metafísica biológica y el problema del conocimiento», Diálogo filosófico, 57, (2003), pp. 384-400. 
de un proceso multicausal (materialmente inconmensurable). Asimismo, a raíz de los descubrimientos de Unger y Hauser ${ }^{10}$-enfocados en los dilemas morales personales e impersonales- y en coherencia con las propias tesis de Wilson -relativas a la propensión humana de mostrar un mayor grado de empatía hacia los congéneres con fines de supervivencia-, Cortina nos plantea lo siguiente:

... cabe preguntar si el fin moral de los seres humanos es «sobrevivir a secas», o si consiste en «vivir bien» [...], lo que no parece posible desde la estricta neurociencia es explicar que la moral humana sea sólo un mecanismo adaptativo ${ }^{11}$.

En efecto: la existencia de un código ético que instaura comportamientos de protección grupal y activa mecanismos garantizadores de la subsistencia de la especie humana no es óbice para reflexionar sobre la importancia del entorno en la estructuración social de los contenidos éticos. De hecho, el aumento de las sociedades actuales demanda un código ético que no solo tenga en cuenta la tendencia innata (biológica) de defender al prójimo, al grupo de iguales, sino también el respecto por la diversidad cultural del «otro».

... si la idea de supervivencia prescribe rechazar al lejano, entonces no es un fin moral, no forma parte de nuestra idea de una vida buena [...] del «es» del mecanismo evolutivo no surge el «debe» moral ${ }^{12}$.

He ahí la razón por la cual la pedagogía y la educación adquieren un rol fundamental: ellas se conciben cual herramientas de socialización capaces de activar o desactivar, potenciar o reprimir, ciertos «interruptores biológicos». Ahora bien, ¿es esto realmente posible de acuerdo con los descubrimientos neuroéticos?, ¿o se trata solo de un afán pedagógico que no tiene en cuenta la fuerza de la determinación biológica sobre la conducta ética? En aras de responder a esta pregunta, cabe traer a colación otro de los debates más destacados de la neuroética: aquel relativo a la diferencia entre la causalidad y la correlación de las variables con las que sus investigaciones operan. Veamos.

Aceptando la evidencia de que existe una estructura cerebral común a todos los seres humanos, la cuestión sobre la importancia -o no- del contexto socializador se resolverá al determinar si las funciones neuronales son causa (arché) de la formulación de juicios morales o, por el contrario, son bases (Grund) para poder formularlos. A nuestro entender, si bien es «indudable que hay bases cerebrales, sociales, psicológicas o económicas sin las que es imposible formular juicios, esto no significa que los causen ${ }^{13}$.

10 Cortina, op. cit., 2010, pp. 133-146.

11 Cortina, op. cit., 2011, pp. 89 y 91.

12 Ibidem, pp. 89-90.

13 Ibidem, p. 83. 
En aras de defender esta tesis, cabe hacer una distinción entre la capacidad innata para articular juicios morales, de un lado, y los contenidos morales que confieren dichas formulaciones, de otro. Nos inspiramos así en las ideas de N. Chomsky ${ }^{14}$ : de acuerdo con él, la existencia de una base biológica constituyente de una suerte de «gramática universal» no implica, al menos necesariamente, la conformación autómata de contenidos semánticos. Y así como, partiendo de una propensión biológica o estructura neuronal universal, pueden generarse lenguas particulares, así también es posible configurar contenidos morales diferentes.

Adviértase en qué medida se acepta así la tesis fundamental de la neuroética (la existencia de una base biológica que determina la conducta ética y el razonamiento moral) sin descuidar el carácter materialmente irreductible o la diversidad cultural de los contenidos morales. En sintonía con Chomsky, nos encontraríamos así ante una "gramática moral que nos permite aprender todos los lenguajes morales»" ${ }^{15}$.

\subsection{NeURoÉTiCA, LENGUAJE Y edUCACIÓN}

Llegados a este punto, cabe añadir que la justificación de la importancia del contexto social y educativo no acaba ahí (en el estatus cultural de los contenidos morales); y es que se estima que prácticamente un $70 \%$ de la capacidad cerebral del humano tiende a desarrollarse en interacción con el entorno ${ }^{16}$. Puesto que el ambiente es capaz de ejercer una influencia significativa en la activación y evolución de nuestros genes, resulta prudente considerar que la estructura biológica no constituye un determinante absoluto en el desarrollo del razonamiento moral. En otras palabras, «el conocimiento depende considerablemente de recursos que van más allá del cerebro y del cuerpo»" ${ }^{17}$; nos referimos, en especial, al entorno y al lenguaje.

Esta última idea sintoniza con la llamada "Teoría de la Mente Extendida», según la cual el aparato mental es definido ya no solo en razón de funciones electroquímicas o neuronales, sino también -y sobre todo- en virtud del medio ambiente. Más específicamente, la "Teoría de la Mente» (ToM) subraya que la empatía es un proceso socioafectivamente constituido: comienza a hacerse palpable en torno a los 2-3 años de edad, momento en el que los seres humanos son capaces de atribuir estados mentales o intencionales a otros individuos ${ }^{18}$. Esto implica que la comprensión de «lo otro» y la preocupación por «el otro» requiere, como resulta lógico, de una apertura socioafectiva. La alteridad medioambiental se vuelve así un elemento

${ }_{14}$ Ibidem, pp. 104-105. Véase también N. Chomsky, Reflections on language, Phanteon, New York, 1975.

15 Ibidem, p. 123.

16 Ibidem, p. 91.

17 Ibidem, p. 134.

18 Tirapu-Ustárroz, J., Pérez-Sáyes, G., Erekatxo-Bilbado, M. y Pelegrín-VaLERo, C. (2007), Revista de neurología, 44 (8), pp. 479-489. 
clave para la constitución de marcos éticos basados en el afecto, primero, y en la lógica, después.

Ciertamente, los postulados neuroéticos no serían posibles sin la debida interacción del «yo» con «los otros», o de «los otros» con «el yo»-de ahí la relevancia que ha adquirido en los últimos lustros la llamada «ética de la alteridad»-. En otras palabras: la identidad individual $-y$, por tanto, la subjetividad moral- requiere como condición de posibilidad que el sujeto se distinga del resto de seres y sea capaz de atribuir significados a la realidad circundante. Así pues, una persona que no ha escuchado palabra alguna durante sus primeros años de vida difícilmente desarrollará un lenguaje con un dominio gramatical pleno ${ }^{19}$. En coherencia con ello, un individuo despojado de su entorno social tampoco será capaz de desarrollar razonamiento moral alguno.

No es casualidad, en función de lo anterior, que actualmente primen las llamadas éticas de la alteridad, así como las éticas discursivas y pragmáticas: allá donde la primera enfatiza el rol constituyente de la alteridad en la persona, las segundas subrayan la acción semiótica implicada en la configuración de categorías morales. En cualquiera de los casos, se trata de éticas que destacan el poder que tiene la palabra para constituir comunidad. De ahí que la performatividad, entendida como un «hacer cosas con palabras», se torne eje articulador fundamental del aparato ético.

\section{LA EDUCACIÓN MORAL: UN ACERCAMIENTO DESDE LA FILOSOFÍA Y LA PSICOLOGÍA COGNITIVA}

Una vez que hemos esclarecido en qué medida las bases neuronales que propician la conducta ética y el razonamiento moral se ven determinadas por el entorno lingüístico, socioafectivo y cultural, en el presente apartado indagaremos sobre las posibilidades de la educación moral.

Para empezar, hemos de tener en cuenta algo ya instaurado en el sentido común de nuestras sociedades occidentales: la educación en los sistemas políticos democráticos es uno de los pilares sociales más importantes. Como eje dinamizador de los conocimientos y saberes, la escuela -en cuanto institución formal educativaha adquirido un rol fundamental en el desarrollo de las sociedades modernas. Concibiendo la escuela como uno de los principales instrumentos de socialización -junto con la familia-, parece evidente estipular que la pretensión de lograr ciertas mejoras o cambios sociales debe abrazar primeramente una adecuada formación cívica.

En lo que respecta a la educación moral, resulta conveniente que las propuestas o discusiones que en torno a ella se generen tengan en cuenta no solo las impli-

19 Dos llamativos casos sobre humanos encontrados con carencias lingüísticas graves se dieron con el nińo salvaje de Aveyron (descubierto en 1724, había crecido a la intemperie de la selva) y Genie (encontrada en 1970, tras 13 años de cruel aislamiento de todo roce afectivo y lingüístico); ambos fueron incapaces de desarrollar unas habilidades comunicativas gramaticales normales a pesar de las ulteriores intervenciones pedagógico-terapéuticas. 
caciones políticas, sino también los descubrimientos científicos que reformulan el marco teórico que la fundamenta. He ahí la razón por la cual nos hemos interesado en la neuroética: ya advertíamos con anterioridad que el diseño de una adecuada educación moral pasa por integrar los descubrimientos y debates que ella entrańa.

Ahora bien, antes de examinar la necesaria integración que la neuroética ha de tener en toda política educativa de la moral, se vuelve necesario subrayar en qué consiste específicamente esta.

\subsection{LA EDUCACIÓN MORAL COMO HERRAMIENTA PARA LA EMANCIPACIÓN}

El término «educación» se diferencia del concepto «adoctrinamiento» en la medida en que el primero, a diferencia del segundo, apunta a un aprendizaje promotor de pensamiento crítico, fomentador de la libertad de acción y expresión. Si bien ambos hacen alusión a un cambio conductual derivado de la adquisición de determinados contenidos teóricos, el «adoctrinamiento» está relacionado con la inculcación de una ideología que tiende a estar exenta de libertad de pensamiento y arbitrio.

Dada esta diferencia, cabe resaltar que no todo proceso de aprendizaje o formación -entendido como construcción de conocimientos y adquisición de destrezas que estimulan un cambio comportamental- supone educar. He ahí la razón por la cual la constitución de una «educación moral» debe implicar algo más que la simple instrucción de ciertos contenidos elegidos selectivamente por un grupo de expertos. Por el contrario, un óptimo desarrollo de los procesos de enseñanza y aprendizaje moral debe incluir la participación activa del primer agente socializado (el alumnado) y de los principales agentes socializadores (las familias y las escuelas).

En razón de lo anterior, estamos de acuerdo con Cortina cuando dice que «educar dando y pidiendo razones cordiales es la forma más adecuada de formar en la autonomía y de evitar la indoctrinación ${ }^{20}$. Siguiendo las ideas de la autora, la base del cultivo de las Habilidades Sociales (HHSS), la capacidad argumentativa y reflexiva, la reciprocidad y la empatía serían los ejes centrales para una adecuada educación moral.

Adviértase, con todo, que enfocar la educación como herramienta de emancipación moral supone integrarla dentro del marco de la denominada "pedagogía progresista». Se trata de una pedagogía cuyos principales promotores -Montessori, Freinet, Pestalozzi, Dewey, Freire, entre otros- defienden la configuración de procesos de enseñanza y aprendizaje democráticos, esto es, centrados en la participación activa, la colaboración y el pensamiento crítico $^{21}$.

Aclarado, pues, el marco teórico que define los límites y las bases de la educación, resta pasar a la siguiente cuestión: teniendo en cuenta las bases neuronales que determinan, aunque sea relativamente, la moralidad, ¿cuál es el momento en el

${ }^{20}$ Cortina, op. cit., 2011, p. 232.

${ }^{21}$ C. Lozano, La Educación en los siglos XIX y XX, Síntesis, Madrid, 1994, pp. 27-109. 
desarrollo del humano propicio para la enseñanza de la misma? En otras palabras: dado que -en concordancia con lo defendido más arriba- el desarrollo de la conducta ética, así como del razonamiento moral, depende tanto de la biología como del entorno, ¿podríamos considerar que hay un momento propicio en la maduración neurológica de la persona que la haga más apta o receptiva al dominio del contenido moral?

Para responder a dicha pregunta, estimamos oportuno traer a colación dos autores paradigmáticos de la psicología del desarrollo: Jean Piaget y Lawrence Kolhberg. Si bien sus teorías se encuentran en constante revisión, constituyen marcos de orientación fundamentales para la temática que nos ocupa. Más específicamente, ellas destacan por responder de manera afirmativa a la cuestión recién planteada, sugiriendo que, en efecto, encontramos en el desarrollo evolutivo del humano ciertos momentos que resultan más favorables para la educación moral. Veamos esto con mayor detenimiento.

\subsection{Dos Pilares teóricos de la educación moral: Piaget y Kolhberg}

Apuntábamos con anterioridad que, dentro del ámbito educativo moral, dos autores destacan sobremanera por sus aportaciones: Jean Piaget (1896-1980), con su teoría epistemológica del conocimiento; y Lawrence Kohlberg (1927-1987), con su teoría del desarrollo moral. Empecemos por el primero.

La principal aportación que realiza Piaget a la psicología, a la antropología e incluso a las ciencias de la naturaleza arraiga en su teoría epistemológica, según la cual el ser humano se desarrolla paralelamente de forma psíquica y motriz a través de una serie de etapas o estadios -los cuales son siempre inclusivos y progresivos-. Más específicamente, cuatro son los estadios que -de acuerdo con el autor-constituyen el desarrollo cognitivo del ser humano: (1) el sensorio-motriz (de 0-3 años aprox.), (2) el preoperacional (de 3-6 años aprox.), (3) el operacional concreto (de 6-12 ańos aprox.), (4) y el operacional formal (a partir de los 12 años) ${ }^{22}$.

En este caso, los estadios de pensamiento «operacional concreto» y «operacional formal» constituirían el fundamento del juicio moral. Si bien durante ambas etapas se consolida el desarrollo del pensamiento complejo, abstracto o lógico-conceptual, la segunda (etapa operacional formal) se diferencia de la primera (etapa operacional concreta) al implicar la sistematización de aptitudes relativas al cálculo de probabilidades, la aplicación de la lógica formal, el razonamiento deductivo, la interpretación de la realidad material mediante el lenguaje matemático, etc. ${ }^{23}$.

Precisamente, ese último estadio del desarrollo cognitivo (el «operacional formal») es el que propicia el manejo riguroso y la comprensión adecuada de dilemas morales. Ahora bien, tal desarrollo no solo depende, de acuerdo con Piaget, de las

22 G. Pinget, Seis estudios de Psicología, Editorial Labor, S.A., Barcelona, 1991, pp. 13-16.

23 Ibidem, pp. 111-124. 
bases biológicas que predisponen al individuo para ello, sino también del entorno. Más específicamente, las operaciones formales se consolidan e integran dentro del razonamiento general del sujeto en la medida en que este interactúa con otros, sean sujetos u objetos del mismo mundo (horizonte de inteligibilidad). De ahí la importancia, en sintonía con lo que venimos diciendo, del contexto educativo en el desarrollo psicomotriz.

Llegados a este punto, cabe advertir lo siguiente: en tanto en cuanto la teoría epistemológica de Piaget -tal y como fue expuesta inicialmente- desembocó en la consideración del estadio «operacional formal» como último y definitivo, han ido apareciendo ulteriores investigaciones que defienden que en la adultez el pensamiento puede seguir madurando o adquirir otros matices ${ }^{24}$. En sintonía con esto último, se ha barajado la posibilidad de ampliar la inicial clasificación piagetiana, incluyendo un ulterior pensamiento "postformal»; este implicaría la razón pragmática, que estudia la aplicación del pensamiento lógico a las necesidades de la vida fáctica, y el juicio reflexivo, comprendido como la capacidad de evaluar la exactitud y coherencia lógica de los argumentos. Se vendrían a suplir así las insuficiencias encontradas en la clasificación propuesta por Piaget ${ }^{25}$.

Nótese que ambos tipos de pensamiento "postformal» sintonizan con lo que cabríamos esperar de una adecuada educación moral. Y es que los problemas a los que hay que hacer frente en la vida diaria no pueden ser abordados únicamente mediante la lógica formal. Precisamente, si algún debate ha caracterizado a la filosofía del siglo xx es aquel concerniente a la crítica de la epistemología positivista y el surgimiento de la epistemología hermenéutica; acontece con ello lo que algunos autores han venido a denominar «el giro fenomenológico-hermenéutico de la ontología».

Por su parte, la teoría de Kohlberg nos muestra que la moralidad, el respeto a las normas sociales y el sentido de la justicia se gestan en la preocupación por la igualdad y la reciprocidad entre las personas. Coherentemente, el autor estima que el desarrollo moral surge de la interacción de los esquemas mentales de los sujetos con las experiencias sociales, especialmente con los iguales. Al igual que Piaget, Kohlberg establece una serie de niveles para explicar el desarrollo moral: el nivel preconvencional (dado en la niñez), el nivel convencional (dado en la adolescencia y en algunos adultos) y el nivel postconvencional (dado en la juventud y adultez) ${ }^{26}$.

De acuerdo con esta clasificación, la madurez del razonamiento moral se alcanzaría a partir del nivel convencional, pues en el primero lo que mueve la conducta ética son variables eminentemente exógenas -tales como el premio y el castigo-. El nivel convencional, por el contrario, se caracteriza por un respeto a las normas convenidas por el grupo al que se pertenece. En este nivel, el sujeto intenta

${ }^{24}$ J.D. Sinnot, Postformal reasoning: The Realistica Stage, en M.L. Commons, F. Richards y C. Armon (eds.), Beyond forman operations: late adolescente and adult cognitive development, Praeger, New York, 1984.

25 Ibidem.

${ }^{26}$ L. KohlBerg, Essays on moral development: The psychology of moral development, San Francisco, Harper and Row. Trad. cast.: Psicología del desarrollo moral, Bilbao, Desclée de Brouwer, 1992. 
cumplir bien su propio rol respondiendo a lo que los demás esperan de él; la vocación personal queda así supeditada al deber social o la integridad comunitaria ${ }^{27}$. Lo que prevalece, en última instancia, es la seguridad y el orden sociopolítico.

Ahora bien, adviértase que la moralidad en el nivel convencional no depende tanto de causas exógenas -aunque también (seguir el régimen social en pos de la integración) - cuanto de razones endógenas - las cuales conciernen al deber individual de contribuir a una sociedad pacífica-. En otras palabras: en el estadio convencional, el orden social y moral establecido adquiere valor en sí mismo, más allá del propio individuo ${ }^{28}$.

El nivel postconvencional, en cambio, apela a valores y principios de validez universal, considerándose moralmente correcta la acción que está de acuerdo con estos principios. Aquí ya no prevalece tanto la convención social cuanto la integridad de los individuos. El peso del razonamiento moral recae, pues, sobre una base esencialmente autónoma o interna. Veamos los dos estadios que, según Kohlberg ${ }^{29}$, se darían en este nivel:

- El estadio 5, relativo al consenso social, establece que el pensamiento moral se basa en el reconocimiento del contrato social y los Derechos Humanos (DDHH) universales. Si bien, como ocurría en el nivel convencional, aquí prevalece también el convenio social, la principal diferencia con respecto a aquel radica en su tendencia universalista. En otras palabras: en este primer estadio del nivel postconvencional, la normatividad moral se articula y fundamenta en unas leyes que tienen por fin el bienestar de la humanidad.

- El estadio 6, por su parte, la reflexión personal en torno a la constitución de una axiología universal prima más que las posibles normativas convenidas. Aunque este estadio comparta con el anterior su afán universalista, la relevancia aquí se le otorga a la persona, así como a su capacidad crítica, y no al colectivo. Si bien se reconoce el valor del contrato social para garantizar los derechos de todos los ciudadanos, se estima que de faltar alguna ley o de ser esta injusta la actuación debe seguir los propios principios morales. En este caso, la perspectiva social alcanza su máxima amplitud, pues engloba a todo arbitrio moral humano.

Adviértase en qué medida estos niveles o estadios del desarrollo moral de Kohlberg nos llevan a una conclusión parecida a la de Piaget: la conducta ética y el razonamiento moral se identifican, clasifican y comprenden siempre en función de un entorno social. La maduración neurológica que resulta correlato del razonamiento moral requiere, pues, de un entorno favorable. En este sentido, diríamos que la orientación moral de las personas es deudora del conjunto de influencias e interacciones que tienen lugar en el contexto sociocultural.

$\begin{array}{ll}{ }_{27} & \text { Ibidem } . \\ { }_{28} & \text { Ibidem } . \\ & \\ & \end{array}$ 


\section{LA NEUROÉTICA Y LOS RETOS EDUCATIVOS EN LA ACTUALIDAD}

Apuntábamos con anterioridad que, más allá de nuestro desacuerdo con el reduccionismo cientificista de la conducta moral, las aportaciones de la neuroética son actualmente necesarias para la configuración de una adecuada educación moral. En otras palabras: nuestra crítica al reduccionismo científico o cognitivo no nos exime de la posibilidad de promover una educación moral basada en los descubrimientos neurocientíficos. De lo que se trata es, entonces, de plantear puntos de convergencia entre los factores endógenos (biológicos) y exógenos (sociales) de la conducta moral. En coherencia con esto, nos dice Cortina:

Qué duda cabe de que las bases cerebrales resultan indispensables para la educación moral. Un ser que careciera de cerebro no podría ser educado [...]. Educar moralmente a un niño no significa adiestrarle para que actúe de la forma que desea el educador [...]. Educar moralmente significa ayudarle a extraer lo mejor de él para que pueda llevar adelante, desde su autonomía, una vida justa y feliz ${ }^{30}$.

He aquí, pues, el reto al que se ven abocados los programas educativos de las actuales sociedades: la armonización de la aportaciones neutoéticas y las investigaciones filosóficas sobre el razonamiento moral ${ }^{31}$. Veamos a continuación, con mayor detenimiento, las implicaciones de susodicho reto.

\subsection{Los Retos aCtuAles De LA EDUCACión MORAL: EL PLAN DE ENSEÑANZA Y APRENDIZAJE}

Uno de los principales retos que se nos plantea a la hora de diseñar una educación moral basada en la neuroética radica, como hemos venido advirtiendo, en la adopción de una postura crítica sobre el propio quehacer científico. La principal función de la filosofía, a este respecto, estriba en identificar qué porcentaje de los datos científicos se debe a una descripción exhaustiva de los hechos neurológicos y cuál es causa de la interpretación que el científico elabora a partir de los mismos.

A partir de entonces, cualquier pedagogo o político de la educación ha de confeccionar un programa capaz de discernir en qué momentos del desarrollo neurobiológico el humano es capaz de integrar mayores -o menores-contenidos morales. Dicho de otra manera: la enseñanza del contenido moral o del razonamiento ético ha de realizarse en aquellas etapas en las que el individuo, por biología, se encuentra más apto para el aprendizaje de un material de ese calibre. Ello no implica, sin embargo, que este no pueda adaptarse para transmitirse a otras edades más tempranas.

30 Cortina, op. cit., 2011, p. 218.
31 Ibidem, p. 217. 
Dicho lo cual, cabe dar paso a otro de los retos actuales de la educación moral; se trata de uno concerniente ya no solo a la elección del contenido, sino también a la metodología. Si el primero nos remite a la dimensión material del proceso de enseńanza y aprendizaje, la segunda nos lleva a la dimensión formal o estructural. Nos referimos, en última instancia, al formato a través del cual los contenidos se comunican.

Teniendo en cuenta que el método implica una «vía de acceso» para, en este caso, el aprendizaje de un determinado contenido o razonamiento moral, cabe disponerlo de una manera amena y significativa. La significación viene a indicar aquí el grado de implicación psicoemocional o socioafectiva del contenido y, por ende, del aprendizaje. En efecto: cuanta mayor significación tenga un contenido, tanto mayor será la solidez de su integración ${ }^{32}$. He aquí la razón por la cual conviene educar moralmente a través de supuestos prácticos o dilemas éticos basados en acontecimientos de la vida diaria. Por ejemplo, las noticias de un periódico se estiman idóneos instrumentos para la educación moral, sobre todo cuando implican contraposiciones de opiniones en las que se encuentra en juego la integridad de una o varias personas.

Con todo, la elección del contenido moral resultará un correlato del diseño metodológico, pues el formato dependerá del material que se quiera transmitir y viceversa. Ambos vendrán determinados, en última instancia, por la edad del aprendiz.

En lo que se refiere, por su parte, al diseño y estructuración de los fines de la educación moral, cabe retomar lo que ya apuntábamos con anterioridad: la educación, ante todo, ha de primar la emancipación del individuo mediante el pensamiento crítico y el desarrollo de facultades tanto epistemológicas (sophia) como ético-políticas (prhrónesis) o técnicas/artísticas (póiesis). Lo que la neuroética nos descubre al respecto de estas facultades estriba en una idea ya planteada por el propio Aristóteles, a saber: el humano se ve inclinado a actuar en razón de un bien mayor. Este es, por lo general, la felicidad, que implica el bienestar.

Si bien la acción moral, como hemos venido dilucidando, se ve determinada por el contenido sociocultural en el que se ve envuelta, también es cierto que el despliegue de la misma depende de unas «bases cerebrales que nos predisponen a actuar de una forma u otra en relación con la autonomía, la justicia y la felicidad $\aleph^{33}$. Así mismo lo atestigua el neurólogo A. Damasio, cuyos descubrimientos nos permiten establecer una correlación entre las estructuras biológicas destinadas a la autopreservación y los afanes de virtud y felicidad ${ }^{34}$.

Aunque el autor ve en los pilares biológicos de la emoción la base de la configuración social y ética, coincide con Cortina en la siguiente idea: el contenido moral relativo al establecimiento del bien y del mal es forjado por una convicción intersub-

32 Ausubel, Novak y Hanesian, Educational Psychology: a cognitive view, Holt Rinehart and Winston, New York, 1968.

${ }_{33}$ Cortina, op. cit., 2011, p. 220.

34 A. Damasio, En busca de Spinoza. Neurobiología de la emoción y los sentimientos, Crítica, Barcelona, 2005. 
jetiva o consensuada. En este sentido, diríamos con Spinoza que no existe el bien y el mal a secas -cual ideas platónicas-, sino lo bueno o lo malo; esto es, lo relativo a un contexto significación o comunicación.

Los seres humanos son como son: vivos y equipados con apetitos, emociones y otros dispositivos de autopreservación, que incluyen la capacidad de saber y razonar. La consciencia, a pesar de sus limitaciones, abre el camino para el conocimiento y la razón que, a su vez, permite a los individuos descubrir qué es bueno y qué malo. De nuevo, el bien y el mal no son revelados sino descubiertos, individual o por acuerdo entre seres sociales ${ }^{35}$.

A la hora de fraguar una educación moral pública conviene, por tanto, potenciar aquellos códigos biológicos que nos inclinan a buscar fuentes de bienestar interpersonal y a encauzar aquellos otros que -según Wilson- nos predisponen a proteger al cercano en detrimento del desconocido. He ahí la importancia que para la educación tiene la selección del contenido moral: aunque biológicamente estemos predispuestos para primar el bienestar del prójimo, culturalmente conviene expandir dicha tendencia hacia el resto de seres humanos.

De lo que, en última instancia, hemos de cuidarnos es de extraer -o de pretender extraer- el contenido moral únicamente de las predisposiciones biológicas. Y es que, acaso, "ies el funcionamiento de esta parte ancestral del cerebro y de las peculiaridades de las hormonas de dónde debe extraerse qué debemos hacer moralmente y cómo debemos educar en las sociedades del s. XXI? ${ }^{36}$.

Recuérdese que, en nuestro caso, respondemos negativamente -aunque de manera relativa, y no absoluta- a la cuestión recién planteada. En efecto: aquí abogamos por una educación que trabaje sobre la selección de los contenidos morales, así como sobre el diseño de su metodología, partiendo de las estructuras biológicas descubiertas por la neuroética. Si el descubrimiento de las bases neurológicas de la conducta moral nos permite abogar por una educación más o menos universal, la diversidad cultural del contenido de los juicios morales nos lleva al respecto de la alteridad constituyente. En este sentido, estamos de acuerdo con Cortina cuando alega:

Entender la ética universal con bases cerebrales como una gramática moral que nos permite aprender todos los lenguajes morales, es decir, hablar el idioma moral de las diferentes culturas, es mucho más acertado que intentar descubrir principios con contenido ${ }^{37}$.

En efecto:

\footnotetext{
35 Ibidem, pp. 166-167.

${ }^{36}$ Cortina, op. cit., 2011, p. 223.

37 Ibidem, p. 123.
} 
... la gramática moral permite a los niños construir sus propios juicios morales a partir del medio cultural en que se inscriben, es decir, construir sus propios juicios ${ }^{38}$.

En conclusión: consideramos oportuno defender una educación moral que tenga en cuenta la universalidad de las bases biológicas que nos definen y la particularidad del ámbito ideológico que nos caracteriza. Todo ello supone abogar por cierto "autonomismo normativo democrático", esto es, por la autonomía de los contenidos axiológicos propiamente dichos, y, por tanto, de las normas que los articulan.

Esta última reflexión nos catapulta al siguiente subapartado, el cual indaga sobre las diferencias entre un "autonomismo normativo democrático» y otro «autoritario".

\subsection{EdUCACIÓN MORAL Y CIUDADANÍA DEMOCRÁTICA: DOS CARAS DE UNA MISMA MONEDA}

Otra de las cuestiones principales que se nos plantean desde la filosofía de la educación moral radica en la función que ella tiene en las sociedades contemporáneas. En este sentido, cabe preguntarse ¿en qué medida la educación moral determina la configuración de sociedades democráticas éticamente virtuosas?

A nuestro entender, el grado de influencia de la educación moral es alta en toda sociedad. Pero no solo la presencia de la misma determina la sociedad civil y política, sino también su ausencia: allá donde la primera influenciaría favorablemente, la segunda incidiría negativamente. Estamos hablando, en última instancia, de una educación moral que resulta correlato de la formación cívica; de una en la que se integra el aprendizaje de derechos y deberes democráticos. En la medida en que la educación moral se considera "el núcleo de la ética política " ${ }^{39}$, conviene que ella se enfoque más allá de la mera lucha por la subsistencia.

Las razones de la exigencia moral no apelan, pues, a la supervivencia del grupo, ni siquiera a la de la especie, sino al valor interno de los seres que no tienen precio sino dignidad ${ }^{40}$.

Así pues, aceptando el hecho de que «la democracia exige algo más que reciprocidad", y que debe ir más allá de la racionalidad instrumental del lucro inmediato, apostamos por una sociedad constitucional basada en el consenso y el respeto de la dignidad personal. La educación, a este respecto, se concibe como una herramienta formativa básica, la cual, sobre la base de la plasticidad neuronal, debe ser responsable de forjar ciudadanos críticos, justos y respetuosos.

\footnotetext{
38 Ibidem, p. 233.

39 Ibidem, p. 235.

40 Ibidem, p. 235.
} 
Sin duda, los procesos de socialización primaria (familia, escuela) son esenciales para el aprendizaje de patrones morales basados en la responsabilidad y la tolerancia. Teniendo en cuenta que los principales ejes articuladores de una democracia son las personas en tanto que ciudadanos, la educación moral se convierte en un proceso formativo cardinal capaz de preparar a los sujetos para el buen ejercicio cívico.

\subsection{EDUCACIÓN MORAL Y CURRÍCULO}

Habida cuenta de lo anterior, la incorporación de la ética en el currículo educativo como asignatura obligatoria y universal se vuelve imperiosa. Aunque pueda parecer una propuesta ambiciosa, lo cierto es que hoy día -más que nunca- podemos decir que estamos preparados para desarrollarla. Las aportaciones teóricas derivadas de los descubrimientos neurocientíficos son, en este sentido, una novedad inexistente hace algunas décadas- que debe ser aprovechada en pos de la formación y el conocimiento.

Asimismo, desde la perspectiva psicopedagógica cabe recordar la importancia de la educación emocional, ya que incluir en el currículo la educación moral desatendiendo la formación emocional sería un descuido. Teniendo en consideración el papel fundamental que juega el entramado emocional en la formulación de los juicios morales, y tomando como referencia los descubrimientos de Damasio ${ }^{41}$, la educación emocional debe instar a una adecuada regulación del temple afectivo, canalizando los sentimientos destructivos y fomentando los constructivos. A este respecto, Cortina recuerda que «aunque resulta difícil controlar las emociones, la corteza prefrontal puede lograrlo» ${ }^{42}$. Por tanto, uno de los propósitos básicos de la educación moral supondría «conseguir que la razón recta coincida con la emoción adecuada ${ }^{43}$.

Los nuevos cambios sociohistóricos que están acaeciendo en la actualidad, junto con las profundas crisis económicas y políticas, requieren respuestas que han de ir de la mano de una adecuada educación emocional y moral. De ahí la demanda que lícitamente se viene dando desde las distintas dimensiones educativas con respecto a la necesidad de reconfigurar la estructura curricular.

Aprender a degustar cordialmente el valor de la dignidad tanto de los seres lejanos como de los cercanos, dando lugar a nuevos vecindarios, tanto de los vulnerables como de los que no parecen serlo; y aprender a razonar desde la estima de ese valor es, en definitiva, un urgente programa educativo para los nuevos tiempos ${ }^{44}$.

41 Damasio, op.cit., 2005.

42 Cortina, op. cit., 2011, p. 230.

43 Ibidem, p. 231.

44 Ibidem, p. 236. 


\section{CONCLUSIÓN Y REFLEXIONES FINALES: LA EDUCACIÓN MORAL COMO MOTOR DE MEJORA SOCIAL}

Dadas las consideraciones anteriores, los análisis aquí planteados pueden muy bien aunarse en torno a la siguiente idea del filósofo alemán Kant: «El hombre llega a serlo por la educación, es lo que la educación le hace ser» ${ }^{45}$.

A modo de ejercicio retrospectivo, puede observarse que a lo largo del presente artículo se han tenido en cuenta, primeramente, los potentes avances de las neurociencias -en general-y de la neuroética -en particular-. Esto nos ha permitido examinar en qué medida la neutoética ha removido la concepción tradicional de la conducta moral subrayando las bases biológicas de la misma. Por otro lado, la diferencia establecida entre la estructura del juicio moral y el contenido del mismo nos ha permitido subrayar el carácter irreductible de la conducta moral. Esta irreductibilidad encontraba un segundo fundamento, a su vez, en la consideración de que la mente no es un compartimento estanco, encerrada en algún sujeto concreto, sino más bien un mecanismo de retroalimentación entre el organismo del sujeto y el medio ambiente. Y así, bajo la tutela de la plasticidad neuronal, se estimó la importancia de concebir los elementos socioformativos y educativos como herramientas básicas para la construcción de ciudadanos moralmente responsables y sociedades éticamente democráticas.

Sobre la base de lo anterior, la tesis que aquí hemos venido a defender es la siguiente: una educación moral adecuada, constituyente de una propicia formación cívica y emocional, ha de tener en cuenta no solo las bases biológicas de la ética -tal y como la neurociencia las muestra-, sino también una serie de factores sociofamiliares, ambientales e institucionales. La frase de Kant expuesta al inicio del presente apartado expresa coherentemente esta idea: como seres sociales, somos resultado de nuestras interacciones, experiencias y aprendizajes, y no solo de nuestra biología. He ahí la importancia que tienen y tendrán en todo proceso educativo el uso de las nuevas tecnologías y medios de comunicación.

Con todo, conviene recordar que el «arte de gobernar y el arte de educar» ${ }^{46}$ requieren para su pleno desarrollo de un ejercicio autónomo y, a su vez, cooperante en el que los sujetos mismos se tornen protagonistas indispensables de la condición moral de su propia existencia.

Recibido: 15 de junio de 2020; ACeptado: 26 de junio de 2020

45 Kant, op. cit, 1083, p. 11.

46 Reflexiona Kant: «Se pueden considerar como los dos descubrimientos más difíciles para la humanidad: el del arte de gobernar a los hombres, y el del arte de educarlos; todavía hoy se discute acerca de estas ideas». Ibid., p. 12. 